\title{
Improving clinical leadership and management in the NHS
}

This article was published in the following Dove Press journal:

Journal of Healthcare Leadership

7 August 2012

Number of times this article has been viewed

\author{
Edward D Nicol ${ }^{1,2}$ \\ 'Department of Cardiology, \\ Royal Brompton Hospital and \\ Harefield NHS Trust, London, United \\ Kingdom; ${ }^{2}$ Clinical Leadership \\ Academy, School of Medicine, Keele \\ University, Staffordshire, United \\ Kingdom
}

\begin{abstract}
The National Health Service (NHS) is one of the UKs most cherished but political public institutions, providing healthcare, free at the point of delivery. The English NHS must make $£ 20$ bn efficiency savings in the next 3 years whilst in the midst of fundamental structural change outlined in the government's Health and Social Care Bill. This paper will explore the history of leadership and management in the NHS; the evolution of clinical leadership; national strategies to improve NHS clinical and managerial leadership and Lord Darzi's pivotal NHS review. It defines the kind of leadership and management required for today's NHS, looking to overcome some of the main challenges such as improving healthcare quality whilst making efficiency savings and engaging grass roots workers to deliver sustainable, long term improvements. Finally this manuscript makes suggestions as to where future investment is required to improve clinical leadership and management in the NHS.
\end{abstract}

Keywords: clinical leadership, healthcare management, national health service

\section{Introduction}

The National Health Service (NHS) is the envy of many wealthy nations, ${ }^{1}$ whose fee-for-service models often leave the least well off, and often those who most require the services of the healthcare system, unable to access them. However the NHS currently faces a huge challenge if it is to survive and continue to deliver on its founding principles, providing healthcare, free at the point of delivery to its citizens.

In 2009 the NHS Chief Executive demanded $£ 20$ bn "efficiency savings" from 2012-2015. The "Nicholson" challenge ${ }^{2}$ stated that better ways of working, rather than more spending, must be found, amidst a warning that if the challenge were not met, either more money would be needed or fewer desirable results would be achieved. In addition to facing the biggest financial challenge in its history, the NHS is also currently in the midst of fundamental structural change as the UK coalition government's Health and Social Care Bill ${ }^{3}$ recently received Royal assent and has become law. The Bill marks the greatest philosophical and practical change to the NHS since its inception in 1948. Whilst the Secretary of State retains ultimate accountability to parliament for the NHS, the main legislative changes are fundamental and far reaching for those who work in the service. Table 1 summarizes the salient points of the Bill.

Whilst the central tenet that the NHS is "free at the point of use" remains unchanged, to critics of the new Bill this is the first step to privatising provision of care and commissioning of services in the NHS. Regardless however of whether NHS staff support, or are critics of, the new legislation, it is apparent strong and clear clinical 
Table I Key elements of the Health and Social Care Bill 2012

$\checkmark$ Primary Care Trusts (PCT) and Strategic Health Authorities (SHA) being abolished and replaced with new Health and Wellbeing boards that will have the remit to improve integration between local government and the NHS

$\diamond$ Around 200 Local Clinical Commissioning Groups (CCG) will take on the responsibility for commissioning services, when deemed competent to do so, making General Practioners (GP) accountable for $60 \%$ of the NHS $f 100 \mathrm{bn}+$ budget, and work with the newly established National Commissioning Board (NCB) to ensure provision of specialist or low volume but critical services

$\checkmark$ Monitor, previously the NHS financial regulator, will now license any "qualified" providers whilst promoting integrated care, regulating CCG, the NCB and service providers in ensuring patient's interests are met and prevent anti-competitive behaviour (such as competition based on price) amongst NHS, private and third sector providers

$\checkmark$ Another new organization, Public Health England, will lead across government, on national public health policy whilst local government will be funded to develop and lead, with local NHS organizations, on local public health issues

$\diamond$ An enhanced national and local patient advocacy service, HealthWatch, will lead on making sure users have a greater voice throughout the system

Adapted from Ham C. The management of the NHS in England. BMJ. 20I2;344:7.

leadership and management of the NHS has never been more important as in these turbulent times.

This paper will explore the history of leadership and management in the NHS; the evolution of clinical leadership; national strategies to improve NHS clinical and managerial leadership; it will assess the academic literature in this field and Lord Darzi's pivotal NHS review. It will define what kind of leadership and management are required to better serve the needs of today's NHS, highlighting the challenges and realities and posing important strategic questions. It will then look at future investment and what is required to support this vision, from training, education and research through to infrastructure support and investment, with the ultimate aim to determine what is required to improve clinical leadership and management in the NHS.

\section{History}

The issue of management and leadership in the NHS has been a bitter and poisonous one since the 1983 Griffiths Report ${ }^{4}$ in which the then Chairman of Sainsbury's supermarkets suggested that the managerial control of hospitals should be given to appropriately trained managers, working closely with doctors. ${ }^{5}$ Despite government endorsing the recommendation that doctors should be involved in health management (including budgets) it was the health managers that were looked to for leadership within the NHS. Whether managers gained influence in relation to doctors during this period is contested ${ }^{6}$ but one can be clear that the medical profession was deeply aggrieved at the real or perceived shift in power and influence and a loss of their autonomy. To compound matters further, many nurses traditionally took up leadership roles as a natural career progression and became health managers, further undermining the traditional medical hierarchy and entrenching the deep animosity and distrust from both sides of the doctor-manager divide. Academic studies have demonstrated that doctors did not, and to a greater or lesser degree still do not "accept the legitimacy of management", and as a result try to undermine managerial power". ${ }^{7}$

Historically there have been many suggestions as to how to improve the Doctor-Manager relationship. These include interdisciplinary education for both doctors and managers and better management research to co-ordinate better care. ${ }^{8}$ Other suggestions include the introduction of management training as part of the medical school curriculum ${ }^{9}$ and increased clinician and manager collaboration as part of clinical networks. ${ }^{10}$ The US healthcare provider Kaiser Permanente is often cited as an organization where these strategies already reap benefits $^{11}$ as will be seen throughout this paper.

\section{The evolution of clinical leadership in the NHS}

The concept of clinical leadership in the NHS arose predominantly from describing the role of nursing staff taking up managerial roles; however the term clinical leader has grown to encompass anyone with a clinical background who occupies a leadership role, whether formal or informal and therefore now includes all healthcare professionals. ${ }^{12}$

Leadership in healthcare is arguably more challenging than in most other public or private sectors. The combination of an inverted power structure, where the autonomous clinicians at the frontline have greater power in the day-to-day decision making than those nominally "in charge" at the top, combined with a patient-led and individual focus by these clinical staff is often counter to a more public health "greatest good for the most" aspiration of health managers leading to an inevitable friction.

Exemplary negotiation and bargaining skills are required by health managers and non-clinical leaders to gain acceptance of clinical change by clinicians, a domain that is still seen by many, if not most, clinicians as their sole preserve. ${ }^{13}$ This friction is further compounded by a communication and language barrier that heightens antagonism between clinicians and managers. ${ }^{8}$ 
Clinicians and managers are both interested in the quality of healthcare delivered. However the use of evidence based medicine and the maintenance of the complex doctor-patient relationship by clinicians contrasts with the use of raw metrics including length of stay, bed capacity and new-to-follow up ratios in outpatient clinics used by managers highlights the gulf in language and culture that exists between these two groups.

The formalisation of clinical leadership, whereby clinicians take greater responsibility for activities that do not just include the provision of treatments to patients but a wider improvement and quality agenda has led to a small number of doctors, nurses and allied health professionals transferring their clinical skills and knowledge into more formal managerial and wider health leadership roles. This is not without risk for clinicians however; clinical autonomy remains a core and prized value for clinicians and there is often significant reluctance on the part of many clinicians (especially doctors) to support others who take on these management and leadership responsibilities. ${ }^{12}$ Further barriers to doctors embracing medical leadership include the fact it is often less well rewarded than alternatives, such as private practice; successful leadership is often seen as less respectable than success in the research or clinical arena and the significant historical cultural "them and us" attitudes persist ${ }^{11,14}$ leading to remarks that these clinicians have defected to the "dark side". ${ }^{15}$

However medical culture was forced to change in light of a more negative public perception of the profession in the UK following clinical crises such as the Shipman murders, and the Bristol pediatric heart surgery and Alder Hey organ retention scandals where professional self-regulation and professional leadership came under intense scrutiny. At the turn of the millennium the NHS Plan ${ }^{16}$ put clinical leadership at its core, recognizing that although there were some outstanding examples of clinical leadership by doctors, few doctors held senior roles in the NHS. Following the subsequent Kennedy ${ }^{17}$ and Shipman ${ }^{14}$ reports a more stringent regulatory agenda was aimed at all clinicians and the requirement for clinical leaders at all levels was identified as a necessity to prevent future failings of this kind and there is some evidence that medical leadership is moving "from the dark side to center stage". ${ }^{18}$

\section{National strategies to enhance clinical leadership and management}

In 2006 the General Medical Council made clear that all practising doctors are responsible for managing resources and have a responsibility to their patients, employers and those who contract their services. ${ }^{19}$ In 2007 clinical leadership was defined as "to motivate, inspire, and promote NHS values, to empower and create a consistent focus on the needs of the patients being served. Leadership is not just to maintain high standards of care, but to transform services to achieve even higher levels of excellence". ${ }^{20}$ During the same year the NHS Institute for Innovation and Improvement, in collaboration with the Academy of Medical Royal Colleges started to address the lack of formal managerial training for doctors, ${ }^{21-24}$ including producing a Medical Leadership Competency Framework (MLCF) (Figure 1). ${ }^{25}$

This document complemented the NHS Leadership Qualities Framework (LQF) ${ }^{26}$ (Figure 2) that had been prepared for the Department of Health as a benchmark and development tool for Chief Executives, executive Directors and senior managerial leaders within the NHS. The competencies described within this framework can be seen to echo those of the wider prevailing leadership agenda with a mirroring of Emotional Intelligence (EI) personal competencies ${ }^{27}$ with "personal qualities" (central circle).

The EI components of self-management and personal management attributes are also strongly reflected in those desirable skills seen under the broad headings of "Setting Direction" and "Delivering the Service". Whilst the LQF tool was designed for top level and senior NHS leaders the MLCF

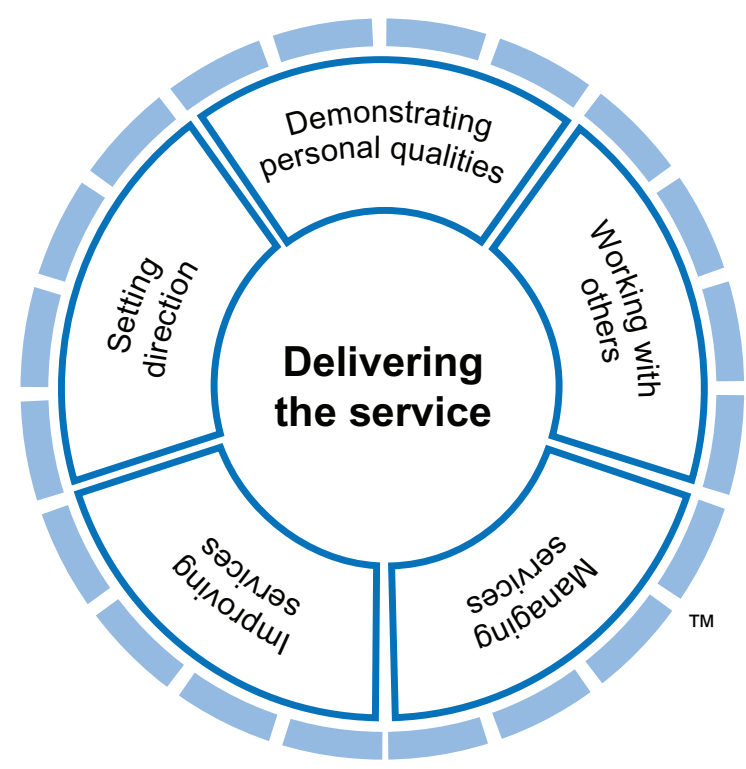

Figure I Medical leadership competency framework.

Notes: NHS Institute for Innovation and Improvement and Academy of Medical Royal Colleges. Medical Leadership Competency Framework. Coventry: NHS Institute for Innovation and Improvement. 2010, 3rd edition. 


\section{NHS leadership qualities framework}

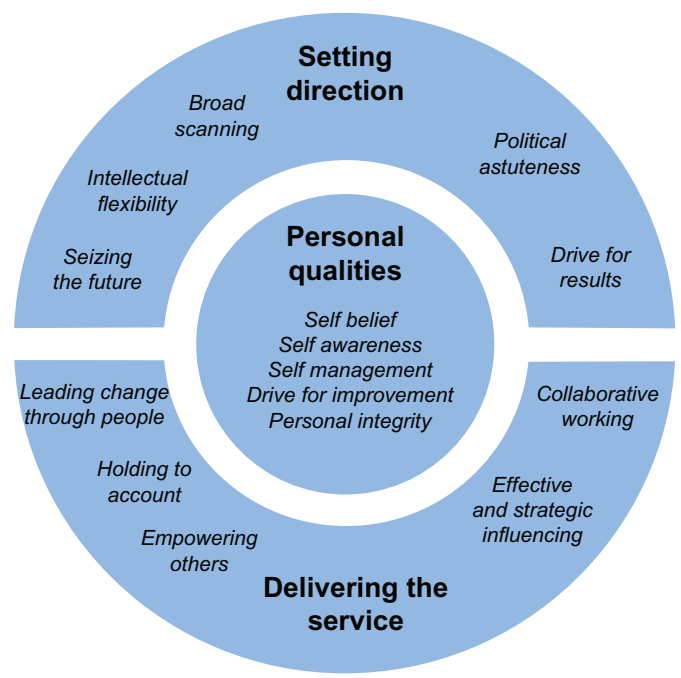

Figure 2 NHS leadership qualities framework. Notes: NHS Institute for Innovation and Improvement. NHS Leadership Qualities Framework. Coventry: NHS Institute for Innovation and Improvement. 2006.

(Figure 1) was designed specifically for doctors (as part of the wider modernizing medical careers (MMC) program). ${ }^{22}$

The MLCF was a benchmarking tool developed to support cumulative health leadership competencies throughout a doctor's medical career. "Personal Qualities" and "Working with others" should be demonstrated by medical students prior to completion of undergraduate training, "Managing and Improving Services" by Specialist (Training) Registrars (Residents) prior to completion of training and "Setting Direction" as a practising consultant clinician. This framework was designed against a backdrop of an increasing political emphasis on shared leadership, even amongst those doctors who do not hold designated leadership roles. It reflected a recognition that many doctors wished to pursue a wider clinical managerial role and the fact that engagement by doctors in the wider health leadership agenda would facilitate yet further engagement by clinicians. ${ }^{28}$

In comparison to the NHS Leadership Qualities Framework, the MLCF contains more managerial leadership focus and is designed more to inform the training and personal development of all doctors, whilst highlighting the need for individual self-assessment and for structured feedback from colleagues. Again the focus on self-awareness and other emotional skills is self-evident and continues to reflect the broader cultural and academic focus of leadership theory.

In 2008, Lord Darzi, a practising surgeon published his review as a junior health minister. He placed significant emphasis on clinical leadership and announced the development of a new NHS National Leadership Council (NLC). He stated "clinicians are expected to offer leadership and, where they have the appropriate skills, take senior leadership and managerial posts in research, education and service delivery". ${ }^{15}$ Furthermore he stated he expected organizations to "allow clinicians the power to affect quality outcomes"15 building on previous aspirations that change in the NHS should be driven by clinicians. His review built on previous work and was endorsed by the UK Royal Colleges who saw the need for their future cadres to embrace the challenge ${ }^{29}$ and stated unequivocally that "if doctors do not accept the [leadership] challenge, they do not deserve to lead". 30

In 2010 the NLC commissioned a new Leadership Framework (Figure 3) "to create a single over-arching leadership framework for all staff groups to enable them to understand

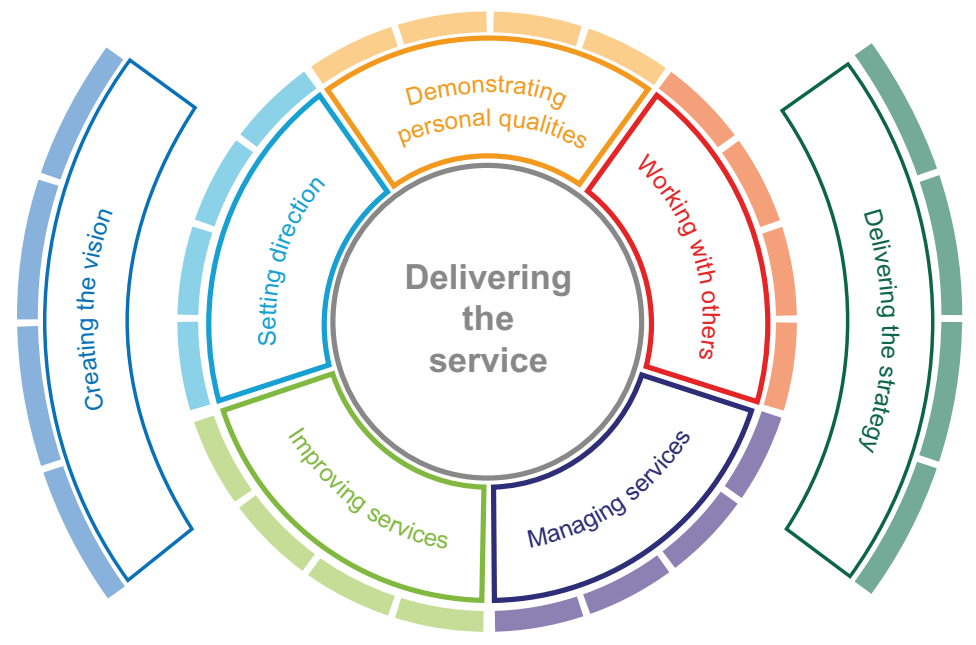

Figure 3 The leadership framework.

Note: NHS Leadership Academy. Leadership Framework. Coventry: NHS Institute for Innovation and Improvement 201 I. 
their progression as a leader and to support the NHS to foster and develop talent". ${ }^{31}$ The premise for this new framework is the concept that leadership is not restricted to people who hold designated leadership roles and that there is a shared responsibility for the success of any healthcare organization or service. It hopes to emphasize the fact that "acts of leadership can come from anyone in the organization and as a model it emphasizes the responsibility of all staff in demonstrating appropriate behaviours, in seeking to contribute to the leadership process and to develop and empower the leadership capacity of colleagues". ${ }^{31}$ The framework also explicitly states that the need for leadership extends from individual's own team and personal responsibilities across the whole sphere of healthcare, whether local service, organizations or whole health economies.

The leadership framework supercedes the LQF (which was decommissioned in October 2011) and further embeds the concept of shared, or distributed leadership and fundamentally sets out to break down the traditional tribal distinction between managers and clinicians.

\section{Academic research in clinical leadership and management}

Academic research on health leadership continues to be sparse, probably due to the complex, turbulent and rapidly transforming industry. ${ }^{32}$ Health care systems are now recognized as complex adaptive organizations ${ }^{33}$ however many educational healthcare scholars have identified what they believe to be necessary competencies of future leaders. ${ }^{34-36}$ The findings are remarkably consistent and include interpersonal skills and emotional intelligence, technical [managerial] skills (in operations, finance, information technology, human resources and strategic planning), industry [corporate] knowledge (both clinical process and health-care institutions), analytical and conceptual reasoning, skills in teamwork, communication and negotiation and an ability to adapt to the changing environment. This data mostly emanates from the USA but is supported by UK leadership academics who also appreciate the need for complex whole systems thinking ${ }^{37}$ within the complexity of socio-political organizational structures. ${ }^{38}$

\section{Defining today's NHS leaders and managers}

The importance of delineating leadership and managerial roles and competencies appears to stem from the perception that there is a tendency in healthcare to use the terms interchangeably. Whilst there is significant overlap, both practically and academically, the two terms are not synonymous.
Amongst the many references available to highlight the differences between them, Baroness Cumberlege's (a former UK Health Minister) and Viscount Slim's quotes address many of the fundamental personal and practical domains that distinguish the two:

"A leader has a capacity to align people to a common set of goals, it is about alignment; a manager brings simplicity to complexity and makes an organisation or process understandable to the masses." ${ }^{39}$

"Leadership is of the spirit, composed of personality and vision, its practice is an art. Management is more of the mind, a matter of calculations and statistics, timetables and routines, its practice is a science." 40

The skills required to provide effective leadership and management in the NHS are broad and numerous. In essence however the domains that must be developed include a collaborative approach to leadership and management, extensive corporate knowledge and skills, a patient centric focus, and suitable personal qualities to lead.

Each of these domains were encapsulated in Lord Darzi's 2008 Next Stage review final report (NSR) ${ }^{15}$ and whilst these have been eclipsed by the more recent Health and Social Care Bill they probably remain the most salient guidance and vision supporting the NHS leadership and management requirement.

Lord Darzi's report sets out a vision to give all current and potential users (patients, carers and the general public) more information and choice about their NHS, encourages true partnership between them and their healthcare providers and puts continuous quality improvement at its core. It proclaims that at a minimum NHS care should be "effective, personal and safe" for all.

Specifically the NHS NSR called for: locally-led, patient centered, clinically driven change; a stronger emphasis on a health and wellbeing service as opposed to the traditional illness service; an NHS responsive to its users and funders; a service truly based on quality as defined by professionals as well as patients and other users; an aspirational healthcare profession striving to deliver world class care, and an NHS constitution enshrining the rights and responsibilities of patients and staff alike. Underpinning this was a fundamental desire for frontline staff to be put in control, to take the lead and responsibility for delivering and implementing this vision.

To further define the requirement to develop the roles of all healthcare staff to support the vision outlined in the NHS NSR a second document was published entitled "A High Quality 
Workforce: NHS Next Stage Review". ${ }^{41}$ This document explained in more detail the requirements of how the NHS NSR would be taken forward by doctors, nurses, midwives, allied health professionals and healthcare scientists.

The report states that to be effective team players staff would have to become practitioners, partners and leaders, using their talents to look beyond their individual clinical practice to a more holistic delivery of healthcare. This would, for example, mean doctors "pulling in the same direction" as others, ${ }^{15}$ working as clinical practitioners but in partnership with others and when necessary taking on leadership roles to deliver high quality care to patients in a truly multiprofessional and multi-disciplinary manner.

Some NHS clinicians and managers are clearly already delivering robust clinical leadership as holistic professionals and as evidenced in the NHS NSR. ${ }^{42,43}$ The exact balance of each of these areas (practitioner, partner, and leader) will vary according to both formal clinical and managerial roles. The NHS NSR review however could be seen as a call to arms for all clinicians and managers to focus on the improvement of the quality, not just quantity of care they provide, both within their organization and the whole $\mathrm{NHS}^{41}$ and to take a leading role.

Building on the NSR the General Medical Council has recently published guidance on "leadership and Management for all Doctors". ${ }^{44}$ This document enshrines the responsibility for all doctors to work beyond their direct clinical care and contribute to improving the quality of services, speak up when things are wrong, deliver training and education and engage fully in planning, using and managing resources. ${ }^{43}$

\section{Challenges and realities}

So it is clear from the literature that the requirement for high quality, corporately focussed, collaborative leaders and managers is required and the national policy has been developed substantially since the turn of the millennium. Taking each of the leadership domains in turn we can see that some progress has been made in each but there remain significant challenges in turning policy into reality, particularly against a constant backdrop of political rhetoric and constant and often conflicting and duplicate demands from government.

Lord Darzi states it is imperative that Acute Trusts and Primary Care Trusts (PCTs) appropriately identify future clinical leaders and support and equip them with the skills they require to manage and lead services and make leadership training "integral to training and development". ${ }^{15}$ However how NHS organizations are supposed to identify and select these individuals and deliver the broad corporate and in-depth managerial competencies identified by academic research remains unclear to this day. The abolition of many of the structures in the new Bill also fundamentally undermines this process. Will the new National Commissioning Board (NCB) or local Clinical Commissioning Groups (CCG) have the capacity and expertise to develop this vital leadership and management agenda in addition to their new commissioning roles?

Much of the focus of the "Nicholson challenge" has focussed on the culling of management and administration costs in the NHS with a stated desire to reduce administration costs by one third and reduced the number of managers and senior managers by $45 \%$. This has, in a large part been achieved in the short term by the disestablishment of PCTs and Strategic Health Authorities (SHAs); however the recent Kings Fund report on the future of leadership and management found whilst the NHS is certainly over administered with "extensive, overlapping and duplicate demands", there was no evidence of over management. ${ }^{45}$ There is also emerging evidence that this culling process is leading to highly skilled and expensive healthcare providers themselves becoming overburdened with administrative tasks rather than delivering healthcare. ${ }^{46}$ It is likely many clinicians will only bemoan the loss of their managerial colleagues, and appreciate their extensive skills, when the horse has well and truly bolted the stable. Reversing these changes will take many years, with a significant loss of highly motivated and skilled staff unwilling to return to an organization that dispatched them for political expediency.

At regional and national levels the demise of PCTs and SHAs will see the loss of many experienced managers, who have worked closely with clinicians in developing and supporting the new CCGs. The NCB and these new local organizations are unlikely to have the capability to fill this vacuum. The Bill makes it clear CCGs should seek expertise from private and third sector organizations however these may not have the same affiliation to the public sector and acquiring this expertise will be costly and certainly not help in the quest to find efficiency savings. ${ }^{47}$

It should also be noted that the concept of practitioner, partner, and leader is taken almost verbatim from the successful US Healthcare provider Kaiser Permanente (KP) who describe their approach to clinical leadership as "healer, leader, and partner". ${ }^{48}$ For all its commendable rhetoric it should also be noted that this approach nearly destroyed KP in its first decade due to its then revolutionary approach to partnership with managers, but ultimately it has been argued that it is the fundamental key to its success. ${ }^{10}$ The author would 
argue that the US and UK models for delivering healthcare are not comparable however and taking the NHS to the brink to see it rise from the flames would be a politically unpalatable path. It should be noted that KP is a homogenous profit-making organization predominantly run by clinicians ${ }^{47}$ whereas the various semi-autonomous, semi-independent organizations that make up the heterogeneous NHS are predominantly run by non-medical chief executives. ${ }^{49}$ Furthermore, due to the quasi-market in the UK healthcare system the ability for individuals to both lead and deliver successfully within say a provider organization (who rely on tariff based activity income) and the wider health economy are often perversely misaligned. No individual is inducted into the NHS; they are employed by, and inducted into, individual trusts and usually their resultant loyalty is to their organization, even if counter to the wider need of the local health economy and NHS. This is exactly the reason that KP chose to do it differently, avoiding the problems of the highly fragmented, disaggregated healthcare structures in the US. ${ }^{10}$ Importantly KP also has a strategic process for management training for physicians that supports the development of future leaders who understand the bedside and the boardroom and make suitable partners for equally well trained managers. ${ }^{10}$

Another of Darzi's schemes involved the rapid expansion of leadership fellowships and opportunities offered to aspirant junior doctors. The National Leadership Council (NLC) included highly successful and motivational junior doctors as emerging clinical leaders on its board ${ }^{50}$ and many also fulfilled high level roles with the Chief Medical Officer, NHS Medical Director and other senior medico-political personnel. ${ }^{51}$ However the author has previously commented that whilst there are many opportunities open to aspiring health leaders, expectations should be realistic both for participants and providers and the potential challenges for junior clinicians should be highlighted alongside the potential rewards. ${ }^{52}$ Whilst a supporter in principle of using this untapped resource, the risks inherent in this approach are numerous; firstly that unmet expectations, in the face of a strong, conservative and hierarchical culture may paradoxically lead to disengagement of these individuals who are both interested in, and capable of ultimately delivering, the necessary innovation and vision required for the NHS in the challenging times ahead; Secondly, trying to "influence without authority" has been a challenging, often isolating and ultimately de-motivating experience for some and whilst junior clinical leadership is both rewarding and exciting, unsupported exposure and isolation can, if not identified and managed, lead to significant anxiety; Thirdly, the selection, timing and perceived elitism and exclusivity of these, often highly vocal individuals, has led some to question the value of this approach, especially when it is perceived by many to have been to the detriment of equally enthused, capable and motivated consultants and middle managers who may have more authority and ability to enable sustained service improvement. There is no doubt many individuals have achieved notable success but a lack of a universal approach to improving leadership and management throughout the whole NHS is notable.

Finally, what of Lord Darzi and his reviews, and the vision he espoused? The new coalition government has inflicted a massive structural upheaval on the NHS with the introduction of a new Health and Social Care Bill, so what of the NHS leadership and management agenda he envisaged? Lord Darzi resigned as a junior minister in the latter days of the previous Labour government, however much of his legacy persists and the NHS executive remains essentially unchanged despite the new government. Whilst names change much continues; In July 2011 it was announced that a new NHS Leadership Academy (NHSLA) was to be launched taking forward the work of the NLC. This has occurred alongside the development of the new Faculty of Medical Leadership and Management, supported by the UK Academy of Medical Royal Colleges working in partnership with (but independently of) the NHSLA. How this new entity will deliver improved healthcare leadership across the NHS remains unclear whilst non-medical professional (such as nurses and midwives) are not members, but it offers the potential to at least unify the leadership agenda for clinicians and managers alike.

\section{Strategic questions}

So the main question in improving the clinical leadership and management of the NHS is not what we need but how to make the policy practice and the vision becomes reality?

It has been acknowledged by the NLC that a multidisciplinary, multi-professional approach is likely to allow greater cross fertilization of ideas between professions. True cross-professional engagement may allow the development of networks of healthcare leaders who can assess complex healthcare issues with real and credible holistic insight with access to colleagues from different clinical backgrounds sharing their insights and perspectives. ${ }^{51}$

However current investment has most often been aimed at doctors or fast track managers and predominantly in a uni-professional setting. This may be appropriate for some but for clinical leadership to flourish there remain several strategic questions that must be answered. Firstly, what is the ultimate aim of the current leadership programs? Is it to raise 
the calibre of future clinical leaders who remain in clinical practice; those who will fulfil senior clinical managerial roles, those who aspire to national and international health management or a combination thereof? Secondly, are we sure we are focussing on, and selecting the right individuals for these programs and is the major focus on trainee doctors the most appropriate strategy given the concerns over lack of authority and clinical credibility? Thirdly how do we capture and disseminate the learning and experiences of these individuals, maximize learning transfer into the workplace and ensure mechanisms such as networks and alumni that may facilitate meaningful dialog and further leadership action that are robust and effective. Fourthly, what weight do we give to the existing leadership programs as compared with individuals who have not undertaken them but present with Health MBAs or Masters qualifications in management and leadership or have gained clinical leadership or managerial experience elsewhere? Finally, but critically over what period and how do we assess return on the significant investment that has been dedicated to these current programs? ${ }^{51}$

Before we decide on how best to invest in the future we must also reflect on what is missing in recent programs. For all the successes of recent years the reality is that the vast majority of NHS staff do not believe that clinical leadership and management is for them, nor that they are empowered to challenge and change the system. Based on the authors own qualitative research it appears many NHS staff perceive the current programs to be elitist and taken up by the ambitious for personal advancement. The generic knowledge of the wider NHS remains woeful, especially amongst doctors and there is no coherent corporate educational strategy.

For the programs that do exist there remains a lack of integration between doctors and healthcare professionals, let alone clinicians and managers. There is almost no patient engagement in this process and yet the author believes a coproductive health leadership model (Figure 4) could harness the skills and expertise of the many millions of users of the system. ${ }^{50}$ Rebranding clinical leadership as "health leadership" has the potential to make it more inclusive and with clinicians, managers and patients working towards a common goal the challenges set by Darzi, ${ }^{15}$ Wanless ${ }^{54}$ and the current Health and Social Care Bill may be attainable. ${ }^{53}$

\section{Investing in the future}

It is clear that a more global and inclusive approach is required to embed this agenda, with appropriate investment in multidisciplinary education and training. It is necessary, within the current constraints of the NHS to fundamentally change the cul- ture towards leadership and management. Whilst the senior NHS leaders and politicians seem to express a consistent message on their strategic aim, and academic research is consistent on the qualities required for successful healthcare leaders; we seem unclear as to how to deliver the change required in the NHS.

The author has previously argued that the UK NHS could learn from the UK Armed Forces leadership model. ${ }^{55}$ In the UK Defence Medical Services (DMS) the ethos and expectation is "Officer first, doctor/nurse/physiotherapist second", and a similar mantra of "NHS first, local organization second" would reinforce a set of behaviours aligned with the NHS mission. Of course there are significant differences between the UK Armed Forces and NHS; the DMS is considerably smaller, it has a different command and control structure and clearer lines of authority, however the underpinning concept that individuals responsibility to the overall service is first and foremost remains a viable approach in the NHS. A strong vibrant health economy will be the bedrock for sustainable and successful healthcare organizations within it. With the emphasis on collaboration now defined in the new Health and Social Care Bill the time is now here to drive this change.

Qualitative research undertaken by the author in this area, utilizing focus groups and semi-structured interviews with senior NHS executives, medical education leaders, health commentators, commercial and charitable providers of health leadership programs and politicians who have previously held ministerial health portfolios, suggests that to fundamentally embed and improve leadership and management within the NHS the following steps should be considered:

1. Ensure top level ownership of the Health Leadership Strategy sits within the National Commission Board (NCB) with a single strategic head.

2. Empower the NHS Leadership Academy and Faculty of Medical Leadership and Management to develop a national framework and curriculum for both generic, corporate NHS training for all NHS staff and higher level health leadership and management curriculum with robust patient engagement, an in-built appraisal system and serially gated competition to the higher (and more costly) elements.

3. Ensure all NHS staff undergo an induction process into the NHS as part of their generic training. For professional groups this training should be weaved into the fabric of undergraduate and postgraduate training, including possible membership examinations for the Medical Royal Colleges. It has to become "the norm" for it to become embedded and has the potential, if associated with a rigorous assessment, appraisal and feedback process, to capture future talent and identify, at an early stage, potential future healthcare leaders. 


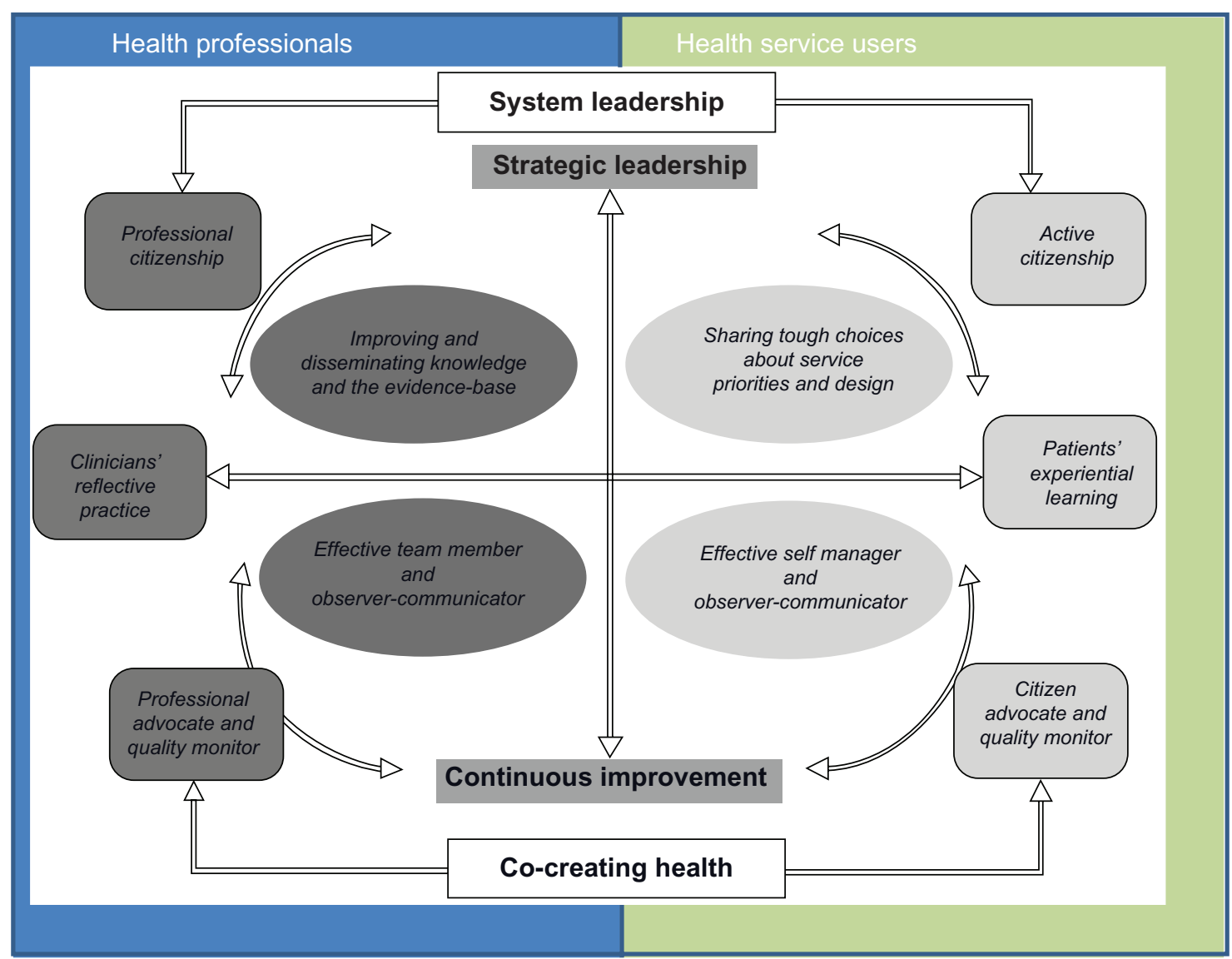

Figure 4 A co-productive health leadership model.

(C) 20 I I Royal Society of Medicine Press, UK. Adapted with permission from Nicol E, Sang R. A co-productive health leadership model to support the liberation of the NHS. JR Soc Med. 20I I; 104:64-68. ${ }^{53}$

4. Devolve the responsibility for the delivery of generic training to the four regional $\mathrm{NCB}$ medical directors. Front line delivery of generic leadership training could be delivered either in-house within the regions, or put out to tender. This would be a matter for local determination.

5. Higher level training should be both practical and have a strong academic component. This should be both in terms of delivery to participants but also to develop evidence to support the funding of such an initiative. Previous research supports the development of a true College of Health Management and Leadership in the UK. This would be most appropriately delivered in conjunction with external providers, both to maintain innovation and allow cross-pollination with partners in finance, management, law and academia. It should maximise the use of simple interventions such as mentoring, and engender habits of successful medical leaders such as encouraging bravery and resilience and optimism, supported by developing networks and action learning. ${ }^{56}$ This model would also allow the NCB to have access to data on individuals who may be appropriate for senior NHS appointments and to whom NHS organizations could turn to when seeking director or board level appointments.

There has been some recent high-level medico-political progress in this direction with the publication of the Innovation: Health and Wealth working group report. ${ }^{57}$ The report specifically states that a major cultural shift is required in the NHS, with greater emphasis on developing staff, both clinical and managerial, and strengthening leadership in innovation at all levels. Within the new NHS structure, Local Education Training Boards have a potential role, using education as a driver for quality improvement whilst Health Innovation Education Clusters and Academic Health Science Networks could become the facilitators for driving innovation, collaboration and adoption. Again the vision appears to be clear but the implementation and embedding of real cultural change remains the challenge and will require appropriately robust funding and political adoption from the outset. There is however evidence that the changes outlined in this manuscript and Health and Wealth review can be successfully implemented with dramatic and enduring effects. The Jönköping County healthcare economy in Sweden has been transformed using similar principles, albeit on a 
smaller scale. With both health and local government support Jönköping is often cited as an example of how to develop a high performing healthcare system. This provides hope for the future, however, it should be noted that this requires sustained political, managerial, and clinical support over many years and an empowered workforce who had "two jobs: to do what they do and to improve what they do". ${ }^{58}$

\section{Conclusion}

The NHS has no choice but to invest in its people if it is to remain viable whilst retaining its founding principles. Whilst it appears that the changes required to make the NHS viable are consistently expressed, politicians and medico-political leaders alike seem unclear as to how to deliver them. It will be a hard sell to get government to invest in robust, multiprofessional, ubiquitous health leadership and management throughout the NHS, however it is a challenge we must rise to if we wish to improve the leadership and management of the NHS in the 21 st century. We must empower all our staff and users to change the system, even in very small ways, or we risk continuing to be wasteful, risk further inexcusable failures and ultimately risk failing in our duty to deliver quality healthcare in the NHS. Without intervention the NHS risks failing as a result of a thousand cuts; however there is the potential to absorb these cuts and emerge as a stronger organization by responding with a million individual ideas delivered by those who see the problems close up: an empowered user group and NHS staff alike.

\section{Provenance statement}

This article is based on the reflection of the author, who has completed both the multidisciplinary Health Foundation Leadership Fellowship 2007-2009 and the 2009/2010 NHS London "Prepare to Lead" scheme. The author has held appointments as a clinical advisor to both the Healthcare Commission and Department of Health and has been involved with the Chief Medical Officers Department as part of both the expert working group and subsequent implementation group seeking to reduce deaths from venous thromboembolism (VTE) in hospitalized patients. The author has an MBA (Health Executive) from Keele University where he is an Honorary Senior Lecturer in the Clinical Leadership Academy and attained the vocational Chartered Manager status through the Chartered Management Institute. He also has an academic interest in leadership both within and outside the health sector and his MBA dissertation explored "The challenges and opportunities of Lord Darzi's leadership agenda". EN is the sole author and guarantor of the article.

\section{Disclosure}

There are no conflicts of interest to declare.

\section{References}

1. Berwick D. Health Foundation 10 year celebration (from a speech at the Science Museum in London to the Health Foundation staff and invited guests) Nov 182008.

2. The Nicholson Challenge. http://en.wikipedia.org/wiki/Nicholson_ challenge. Accessed March 4, 2012.

3. Department of Health. Equity and Excellence: Liberating the NHS. London: The Stationery Office; 2010.

4. Department of Health and Social Security. Griffiths Report: NHS Management Inquiry. London: HMSO. 1983.

5. Ham C. Health Policy in Britain. New York: Palgrave Macmillan. 2004.

6. Harrison S. National Health Service Management in the 1980's. Avebury; 1994.

7. Bate P. Changing the culture of a hospital: from hierarchy to networked community. Public Administration. 2000;78:485-512.

8. Nash DB, Malcolm LW, Barnett P, Hendry C, Crosson FJ, Atun RA, et al. Improving the Doctor- Manager relationship. BMJ. March 22, 2003;326(7390):652.

9. Atun RA. Doctors and managers need to speak the same language. $B M J$. March 22, 2003;326(7390):655.

10. Thomas H. Clinical networks for doctors and managers. BMJ. March 22, 2003;326(7390):655.

11. Crosson FJ. Kaiser Permanente: A propensity for partnership. BMJ. March 22, 2003;326(7390):654.

12. Stanton E, Lemer C, Mountford J. Clinical Leadership: Bridging the Divide. London: Quay Books; 2010.

13. Goodwin N. Leadership in Health Care: A European Perspective. London: Routledge; 2006.

14. Department of Health. Shipman Enquiry Fifth Report-Safeguarding Patients: Lessons from the Past-Proposals for the Future. London: HMSO, Cmnd 6394; 2004.

15. Darzi A. High Quality Care for All - NHS Next Stage Review Final Report. London: HMSO Cmnd 7432; 2008.

16. Department of Health (DH). NHS Plan. London: HMSO. 2000.

17. Department of Health, (DH). The Report of the Public Inquiry into children's heart surgery at the Bristol Royal Infirmary 1984-1995. London: HMSO Cmnd 5207(1); 2001.

18. Spurgeon P, Clark J, Ham C. Medical Leadership: From the Dark side to centre stage. Oxford: Radcliffe Press; 2011.

19. General Medical Council. Management for Doctors. London: General Medical Council; 2006.

20. Department of Heath (DH). Our NHS, Our Future: NHS Next Stage Interin Report. London: HMSO Cmnd; 2007.

21. NHS Institute for Innovation and Improvement and Academy of Medical Royal Colleges. Engaging Doctors: What Can We Learn from Trusts with High Levels of Medical Engagements? Coventry: NHS Institute for Innovation and Improvement; 2011.

22. NHS Institute for Innovation and Improvement and Academy of Medical Royal Colleges. Engaging Doctors: Can Doctors Influence Organisational Performance? Coventry: NHS Institute for Innovation and Improvement; 2008.

23. NHS Institute for Innovation and Improvement and Academy of Medical Royal Colleges. Engaging Doctors in Leadership: What Can We Learn from International Experience and Research Evidence? Coventry: NHS Institute for Innovation and Improvement; 2008.

24. NHS Institute for Innovation and Improvement and Academy of Medical Royal Colleges. Medical Chief Executives in the NHS: Facilitators and Barriers to Their Career Progress. Coventry: NHS Institute for Innovation and Improvement; 2010.

25. NHS Institute for Innovation and Improvement. Medical Leadership Competencies Framework'. Coventry: NHS Institute for Innovation and Improvement; 2010. 
26. NHS Institute for Innovation and Improvement. NHS Leadership Qualities Framework. Coventry: NHS Institute for Innovation and Improvement; 2006.

27. Goleman D. Emotional Intelligence. New York: Bantam Books; 2005.

28. Tooke J. Aspiring to Excellence. London: Aldridge Press; 2008.

29. Gilmore I, Shepherd S. Future Physician: changing doctors in changing times. Clinical Medicine. 2010;10:218-219.

30. Royal College of Physicians. Future Physicians: Changing Doctors in Changing Times. London: Royal College of Physicians. 2010.

31. Development of the Leadership Framework. http://nhsleadershipframe work.rightmanagement.co.uk/. Accessed April 4, 2012.

32. Ford R. Complex leadership competency in healthcare: towards framing a theory of practice. Health Services Management Research. 2009;22: $101-114$

33. Begun J, Dooley K, BZ. Healthcare organisations as complex adaptive systems. In Mick SM, WM, Advances in Healthcare Management. San Francisco: Jossey Bass. 2003.

34. Calhoun JG, Vincent VT, Baker GR, Butler PW, Sinioris ME, Chen SL. Competency identification and modelling in healthcare leadership. Journal of healthcare administration eduacation. 2004;21:419-440.

35. Cherlin E, Halfand B, Elbel BB, Bradley EH. Cultivating next generation leadership: preceptors' rating of competencies in postgraduate administrative residents and fellows. Journal of Healthcare Adminstration Education. 2006;4:351-365.

36. Mouradian WE, Hebner CE. Future directions in health leadership training of MCH professionals: cross-cutting MCH leadership competencies. Mater Child Health. 2007;3:208-211.

37. Bennington J, Hartley J. "Whole Systems Go" Improving Leadership Across the Whole Public Sector System. London: National School of Government; 2009.

38. Grint K. Wicked problems and clumsy solutions: the role of leadership. Clinical Leader. 2008;1:54-69.

39. Personal Interview with Baroness Cumberlege; 2010.

40. Stewart, Rosemary 1996. 'Leadership' in Leading in the N.H.S: A Practical Guide. 2nd edn. MacMillan Business, Chapter one pp. 3-13.

41. Darzi A. NHS Next Stage Review: A High Quality Workforce. London: HMSO, Cmnd 10134; 2008.

42. Royal College of Physicians. Doctors in Society. London: Royal College of Physicians; 2005.

43. Kings Fund RC. Harnessing Professionalism. London: Kings Fund; 2008.
44. General Medical Council. Leadership and Management for all Doctors. General Medical Council; 2012.

45. The Kings Fund.The Future of Leaders and Managers in the NHS. The Kings Fund; 2011.

46. NHS Confederation, Independent Healthcare Advisory Services. What is it all For? Removing unnecessary bureaucracy in legislation. London: NHS Confederation available at: http://www.nhsconfed.org/Publications/ Documents/Whats_it_all_for.pdf. Accessed April 4, 2012

47. Ham C. The management of the NHS in England. BMJ. 2012;344:7.

48. Mountford J WC. Clinical Leadership; Unlocking High Performance in Healthcare. London: McKinsey \& Co; 2008.

49. Ham C, Clark J, Spurgeon P, Dickinson H, Armit K. Medical Chief Executives in the NHS: Facilitators and Barriers to their Career Progress. Warwick: NHS Institute for Innovation and Improvement; 2010.

50. Department of Heath. 'National Leadership Council ', London, HMSO, Cmnd 11183; 2009.

51. Ellis BM, Rutter P, Greaves F, Noble D, Lemer C. New Models of Clinical Leadership: The Chief Medical Officers Clinical Advisors Scheme. The International Journal of Clinical Leadership 2011;17(1):1-6.

52. Nicol E. Capitalizing on Clinical Leadership Fellowships. Clinical Medicine. 2011;11(2):125-127.

53. Nicol E, Sang R. A co-productive health leadership model to support the liberation of the NHS. JR Soc Med. 2011;104:64-68. DOI 10.1258/ shorts.2010.100339

54. Wanless D. Securing Our Future Health: Taking a Long-Term Final Report. London: HM Treasury; 2002.

55. Nicol E. Can the NHS learn from Military Medical Leadership? Health Service Journal; http://www.hsj.co.uk/home/clinical-leaders/ nhs-clinical-leaders-take-a-leaf-from-the-militarys-book/5001387. article; 2009.

56. Warren O, Stanton E. Seven habits of emerging medical leaders. Health Service Journal. March 22, 2012:28-30.

57. Department of Health. Innovation: Health and Wealth. Accelerating adoption and diffusion in the NHS. London HMSO Cmnd 16978; 2011.

58. Baker GR. Leadership in High Performing Healthcare Systems. Department of Health Policy, Management and Evaluation, University of Toronto 2011 available at: http://www.kingsfund.org.uk/document rm?id=9117. Accessed April 11, 2012.
Journal of Healthcare Leadership

\section{Publish your work in this journal}

The Journal of Healthcare Leadership is an international, peer-reviewed, open access journal focusing on leadership for the health profession. The journal is committed to the rapid publication of research focusing on but not limited to: Healthcare policy and law; Theoretical and practical aspects healthcare delivery; Interactions between healthcare and society and evidence-based practices;

\section{Dovepress}

Interdisciplinary decision-making; Philosophical and ethical issues; Hazard management; Research and opinion for health leadership; Leadership assessment. The manuscript management system is completely online and includes a very quick and fair peer-review system. Visit http://www.dovepress.com/ testimonials.php to read real quotes from published authors. 